[Article]

\title{
Al-Fe-P 三元系的热力学优化
}

\author{
曹战民 ${ }^{1, *}$ 谢 伟 ${ }^{1}$ 王昆鹏 ${ }^{1}$ 牛春菊 ${ }^{2}$ 杜广巍 ${ }^{1}$ 乔芝郁 ${ }^{1}$ \\ ('北京科技大学钢铁冶金新技术国家重点实验室, 冶金与生态工程学院, 北京 100083; \\ ${ }^{2}$ 北京科技大学材料科学与工程学院, 北京 100083$)$
}

\begin{abstract}
摘要: 采用 CALPHAD 方法对 Al-Fe-P三元系进行了热力学评估, 并根据相关的实验数据对边际二元系 Al-P 进行了热力学再优化, $\mathrm{Al}-\mathrm{Fe}$ 和 Fe-P边际二元系的热力学参数取自之前的研究并做了局部调整. 根据相图数据 和热力学数据优化了 Al-Fe-P 三元系的热力学模型参数, 获得了体系中所有相的 Gibbs 自由能表达式. 所得参 数之间自洽且能很好地重现 Al-Fe-P 体系的大部分实验相图信息. 通过驱动力判据和本文优化所得的模型参 数, 从热力学上解释了该体系非晶形成能力与组成之间的关系.
\end{abstract}

关键词: Al-Fe-P; 相图; 热力学; 评估; 非晶形成能力

中图分类号: $\mathrm{O} 642$

\section{Thermodynamic Optimization of the Al-Fe-P Ternary System}

\author{
CAO Zhan-Min ${ }^{1, *} \quad$ XIE Wei ${ }^{1} \quad$ WANG Kun-Peng ${ }^{1} \quad$ NIU Chun-Ju² \\ DU Guang-Wei ${ }^{1} \quad$ QIAO Zhi-Yu' \\ ('State Key Laboratory of Advanced Metallurgy, School of Metallurgical and Ecological Engineering, \\ University of Science \& Technology Beijing, Beijing 100083, P. R. China; ${ }^{2}$ School of Materials Science and Engineering, \\ University of Science \& Technology Beijing, Beijing 100083, P. R. China)
}

\begin{abstract}
A critical thermodynamic optimization of the Al-Fe-P ternary system was performed using the CALPHAD method. Among the sub-binary systems in the Al-Fe-P system, the Al-P system was reassessed according to its related experimental information. The thermodynamic descriptions of the Al-Fe and Fe-P binary systems were taken from previous studies with minor modifications. The parameters of the thermodynamic model of the Al-Fe-P ternary system were optimized based on available experimental phase diagram data and thermodynamic properties. One set of consistent parameters of the Gibbs energies of all phases, which can satisfactorily reproduce most of the experimental phase diagram data, was obtained. By employing the driving force criterion with the present thermodynamic description, the experimentally reported composition dependence of the glass-forming ability of the Al-Fe-P system could be explained thermodynamically.
\end{abstract}

Key Words: Al-Fe-P; Phase diagram; Thermodynamics; Optimization; Glass forming ability

\section{Introduction}

Phosphorus has known to be an essential metalloid element in forming an amorphous phase exhibiting useful engineering properties, such as, the Invar effect, ${ }^{1}$ corrosion resistance, ${ }^{2}$ and catalysis. ${ }^{3}$ The Al-Fe-P ternary system has drawn more and more attention due to that amorphous phase formation has been found in the Al-Fe-P system by using a melt-spinning technique. ${ }^{4}$ The evaluation of the glass-forming ability (GFA) of alloys is of great importance by judging in advance whether amorphous phases could be formed at given conditions. The successful evaluation ${ }^{5-7}$ of

Received: April 1, 2013; Revised: July 15, 2013; Published on Web: July 29, 2013.

"Corresponding author. Email: zmcao@ustb.edu.cn; Tel: +86-10-62332530.

The project was supported by the National Natural Science Foundation of China $(50934011,51274034)$ and Fundamental Research Funds for the Central Universities, China (FRF-SD-12-010A).

国家自然科学基金(50934011, 51274034)和中央高校基础研究基金(FRF-SD-12-010A)资助项目

(c) Editorial office of Acta Physico-Chimica Sinica 
GFA of some alloys indicates that the expressions of the Gibbs energies of the phases are very powerful in qualitatively analyzing the composition dependency of the GFA. The Al-Fe-P system is also a fundamental ternary system of the Fe-based and P-containing multi-component alloys, which are very important for the advanced metallurgy and materials. Knowledge of the thermodynamic properties of the Al-Fe-P system is significant for the development of Fe-based and P-containing multi-component alloys by providing information regarding the phases that are present at service temperature, their compositions and volume fractions and so on. Therefore, the interest in this system is increasing, as shown by a recent publication, ${ }^{8}$ in which, however, the researchers only gave a description of the Fe rich side and merely accounted for one isothermal section at $723 \mathrm{~K}$ during the calculation.

Thus, our study was aimed to give a thermodynamic optimization of the Al-Fe-P system over the whole composition range based on all available experimental information in the literature by using CALPHAD (CALculation of PHAse Diagram) approach with Thermo-Calc software package. ${ }^{9}$ The optimized self-consistent thermodynamic parameters of the Al-Fe-P system are expected to be helpful for both the better understanding of the composition dependency of the GFA in the Al-Fe-P system and the development of the Fe-based and P-containing multi-component alloy thermodynamic database.

\section{Information on the binary and the ternary systems}

\subsection{Al-P system}

The Al-P system was extensively investigated by many researchers. White et al..$^{10}$ released the existence of only one intermediate phase, AlP, which was further confirmed by Panish and Ilegems ${ }^{11,12}$ during the study of the Ga-rich corner of the GaAl-P ternary system. Tu et al..$^{13}$ confirmed the existence of AlP again in the investigation of the $723 \mathrm{~K}$ isothermal section of the Al-P-Zn ternary system with the help of combined techniques of optical microscopy, scanning electron microscopy coupled with energy dispersive X-ray spectroscopy (SEMEDS), and X-ray diffraction (XRD). Kischio ${ }^{14}$ reported the melting point of AlP to be $(2803 \pm 50) \mathrm{K}$ without experimental detail. Czochrallski ${ }^{15}$ established a possible upper limit to the solubility of $\mathrm{P}$ in $\gamma$-Al of 0.0007 at mole fraction of $\mathrm{P}$.

Several researchers experimentally measured the heat of formation of AlP using different methods and large difference existed among the experimental results. Kischio ${ }^{14}$ obtained $\Delta_{\mathrm{f}} H_{295 \mathrm{~K}}$ $($ AlP $)=(-82630 \pm 1050) \mathrm{J} \cdot \mathrm{mol}^{-1} \cdot$ atom $^{-1}$ from the heat of dissolution of AlP in aqueous $\mathrm{HCl}$ and the known formation of the products. Wang and Zaheervuddin ${ }^{16}$ measured the heats of combustion of AlP and equal mol mixtures of $\mathrm{Al}$ and red P. Adjusting their results to white $\mathrm{P}$ as reference state, $\Delta_{\mathrm{f}} H_{298 \mathrm{~K}}(\mathrm{AlP})=$ $(-69500 \pm 4600) \mathrm{J} \cdot \mathrm{mol}^{-1} \cdot$ atom $^{-1}$ was obtained. Maria et al. ${ }^{17}$ measured the partial pressures of $\mathrm{Al}$ and $\mathrm{P}_{2}$ vapor equilibrium with AlP, from 1270 to $1800 \mathrm{~K}$ using the Knudsen effusion method in combination with mass spectrometry, and $\Delta_{\mathrm{f}} H_{298 \mathrm{~K}}$ $($ AlP $)=(-59000 \pm 6700) \mathrm{J} \cdot \mathrm{mol}^{-1} \cdot$ atom $^{-1}$ was obtained. A second law fit to Maria's experimental results ${ }^{17}$ was carried out by McAlister $^{18}$ and $\Delta_{\mathrm{f}} H_{298 \mathrm{~K}}(\mathrm{AlP})=(-57600 \pm 17700) \mathrm{J} \cdot \mathrm{mol}^{-1} \cdot$ atom $^{-1}$ with statistical error was yielded. Martosudirdjo and Pratt ${ }^{19}$ reported $\Delta_{\mathrm{f}} H(\mathrm{AlP})=(-74000 \pm 900) \mathrm{J} \cdot \mathrm{mol}^{-1} \cdot$ atom $^{-1}$ using precipitation calorimetry in liquid $\mathrm{Sn}$ at $582 \mathrm{~K}$.

Tu et $a l .^{13}$ gave a description of the Al-P binary system during the thermodynamic analysis of the Al-P-Zn ternary system. Unfortunately, their description could not reflect the phase relation of AlP with other phases correctly when extrapolating the parameters into the Al-Fe-P ternary system. Therefore, the thermodynamic parameters of the Al-P system were re-optimized in this work.

\section{$2.2 \mathrm{Al}-\mathrm{Fe}$ and Fe-P binary systems}

In the Al-Fe system the equilibrium phases are the liquid, the $\alpha$-Fe solid solution based on body-centered cubic (bcc) Fe, the $\gamma$-Fe solid solution based on face-centered cubic (fcc) Fe, the AlFe formed through ordering of $\alpha$ - $\mathrm{Fe}, \mathrm{Al}_{13} \mathrm{Fe}_{4}, \mathrm{Al}_{5} \mathrm{Fe}_{2}, \mathrm{Al}_{2} \mathrm{Fe}$, $\mathrm{Al}_{5} \mathrm{Fe}_{4}$, and the $\gamma$-Al based on fcc Al. Many researchers, including Kaufman and Nesor, ${ }^{20}$ Saunders and Rivlin ${ }^{21}$ and Seier$\operatorname{stein}^{22}$, optimized the Al-Fe binary system. The assessment by Seierstein $^{22}$ is the first consistent description of the Al-Fe phase diagram and has been successfully extrapolated to the related ternary system by many researchers. ${ }^{23-25}$ Thus, the parameters optimized by Seierstein ${ }^{22}$ have been adopted in present assessment, except that the thermodynamic parameters of $\mathrm{Al}_{2} \mathrm{Fe}$ phase have been slightly modified to ensure the $\mathrm{Al}_{2} \mathrm{Fe}$ phase be stable in the Al-Fe-P ternary system. The optimized parameters are shown in Table 1, and the calculated Al-Fe phase diagram is shown in Fig.1(a).

The Fe-P system is composed of the liquid, the $\alpha$-Fe solid solution based on bcc Fe, the $\gamma$-Fe solid solution based on fcc Fe, $\mathrm{Fe}_{3} \mathrm{P}, \mathrm{Fe}_{2} \mathrm{P}, \mathrm{FeP}, \mathrm{FeP}_{2}, \mathrm{FeP}_{4}$, and $\mathrm{P}$ (red and white P). A critical assessment of the Fe-P system has been carried out by Okamoto, ${ }^{26}$ $\mathrm{Ohtani}^{27}$ and Tokunaga ${ }^{28}$ et al. However, in all these evaluations the valuable thermodynamic properties in the Fe-P system measured by Zaitsev et al. ${ }^{29}$ using differential scanning calorimetry and Knudsen effusion method with mass-spectrometric analysis of the gaseous phase were omitted. Most recently, a thermodynamic re-optimization of the Fe-P system has been carried out by Cao et al., ${ }^{30}$ and satisfactorily reproduced most experimental phase diagram and thermodynamic properties. Hence, the parameters assessed by Cao et al. ${ }^{30}$ with minor modification were used in present work. The modified parameters and calculated phase diagram of Fe-P system are shown in Table 1 and Fig.1b, respectively.

\subsection{Al-Fe-P ternary system}

Because of the high volatilization of $\mathrm{P}$, the Al-Fe-P ternary phase diagram has been studied only for the Fe rich corner of this system. Vogel and Klose ${ }^{31}$ studied the phase equilibria in the $\mathrm{Fe}-\mathrm{Fe}_{2} \mathrm{P}-\mathrm{AlP}-\mathrm{Fe}_{50} \mathrm{Al}_{50}$ region of the Al-Fe-P ternary system using differential thermal analysis (DTA) and metallography 
Table 1 Optimized thermodynamic parameters for the binary and ternary systems

\begin{tabular}{|c|c|c|c|c|}
\hline System & Phase & Model & Thermodynamic parameters $/\left(\mathrm{J} \cdot \mathrm{mol}^{-1} \cdot\right.$ atom $\left.^{-1}\right)$ & Ref. \\
\hline \multirow[t]{10}{*}{$\mathrm{Al}-\mathrm{Fe}$} & liq & $(\mathrm{Al}, \mathrm{Fe})_{1}$ & ${ }^{0} L_{\mathrm{Al}, \mathrm{Fe}}^{\mathrm{liq}}=-91976.5+22.1314 T,{ }^{1} L_{\mathrm{Al}, \mathrm{Fe}}^{\mathrm{liq}}=-5672.58+4.8728 T,{ }^{2} L_{\mathrm{Al}, \mathrm{Fe}}^{\mathrm{liq}}=121.9$ & 22 \\
\hline & $\alpha$ & $(\mathrm{Al}, \mathrm{Fe})_{1}$ & ${ }^{0} L_{\mathrm{A}, \mathrm{Fe}}^{\alpha}=-122960+31.9888 T, \quad{ }^{1} L_{\mathrm{Al}, \mathrm{Fe}}^{\alpha}=3089.2$ & 22 \\
\hline & $\gamma$ & $(\mathrm{Al}, \mathrm{Fe})_{1}$ & ${ }^{0} L_{\mathrm{Al}, \mathrm{Fe}}^{\gamma}=-76066.1+18.6758 T,{ }^{1} L_{\mathrm{A}, \mathrm{Fe}}^{\gamma}=21167.4+1.3398 T$ & 22 \\
\hline & $\mathrm{AlFe}$ & $(\mathrm{Al}, \mathrm{Fe})_{0.5}(\mathrm{Al}, \mathrm{Fe})_{0.5}$ & $G_{\mathrm{Al:Al}}^{\mathrm{AIFe}}=G_{\mathrm{Fe} \cdot \mathrm{Fe}}^{\mathrm{AIFe}}=0, G_{\mathrm{Al}: \mathrm{Fe}}^{\mathrm{AFe}}=G_{\mathrm{Fe}: \mathrm{Al}}^{\mathrm{AlFe}}=-14300.9572$ & 22 \\
\hline & $\mathrm{Al}_{5} \mathrm{Fe}_{2}$ & $(\mathrm{Al})_{0.7143}(\mathrm{Fe})_{0.2857}$ & $G_{\mathrm{Al}: \mathrm{Fe}}^{\mathrm{Al}_{\mathrm{Fe}} \mathrm{Fe}}=0.7143 G_{\mathrm{Al}}^{\mathrm{fec}}+0.2857 G_{\mathrm{Fe}}^{\mathrm{bcc}}-32653.7+6.99929 T$ & 22 \\
\hline & $\mathrm{Al}_{2} \mathrm{Fe}$ & $(\mathrm{Al})_{0.6667}(\mathrm{Fe})_{0.3333}$ & $G_{\mathrm{Al}: \mathrm{Fe}}^{\mathrm{A} \mathrm{Fe}}=0.6667 G_{\mathrm{Al}}^{\mathrm{fcc}}+0.3333 G_{\mathrm{Fe}}^{\mathrm{bcc}}-33000+6.36667 T$ & this work \\
\hline & $\mathrm{Al}_{13} \mathrm{Fe}_{4}$ & $(\mathrm{Al})_{0.6275}(\mathrm{Fe})_{0.235}(\mathrm{Al}: \mathrm{Va})_{0.1375}$ & $G_{\mathrm{Al}: \mathrm{Fe}: \mathrm{Al}}^{\mathrm{Al}_{\mathrm{l}} \mathrm{e}_{4}}=0.765 G_{\mathrm{Al}}^{\mathrm{fcc}}+0.235 G_{\mathrm{Fe}}^{\mathrm{bcc}}-30714.4+7.44 T$ & 22 \\
\hline & & & $G_{\mathrm{Al}: \mathrm{Fe}: \mathrm{V}_{\mathrm{a}}}^{\mathrm{Al}_{1} \mathrm{Fe}_{4}}=0.6275 G_{\mathrm{Al}}^{\mathrm{fcc}}+0.235 G_{\mathrm{Fe}}^{\mathrm{bcc}}-27781.3+7.2566 T$ & 22 \\
\hline & $\mathrm{Al}_{5} \mathrm{Fe}_{4}$ & $(\mathrm{Al}, \mathrm{Fe})_{1}$ & $G_{\mathrm{Al}}^{\mathrm{Al}_{5} \mathrm{Fe}_{4}}=G_{\mathrm{Al}}^{\mathrm{fcc}}+12178.9-4.813 T, G_{\mathrm{Fe}}^{\mathrm{Al}_{5} \mathrm{Fe}_{4}}=G_{\mathrm{Fe}}^{\mathrm{bcc}}+5009.03$ & 22 \\
\hline & & & ${ }^{0} L_{\mathrm{Al}, \mathrm{Fe}}^{\mathrm{Al}_{\mathrm{f}} \mathrm{Fe}_{4}}=-131649+29.4833 T,{ }^{1} L_{\mathrm{Al}, \mathrm{Fe}}^{\mathrm{Al}_{\mathrm{F}} \mathrm{Fe}_{4}}=-18619.5$ & 22 \\
\hline \multirow[t]{8}{*}{ Fe-P } & liq & $(\mathrm{Fe}, \mathrm{P})_{1}$ & ${ }^{0} L_{\mathrm{Fe}, \mathrm{P}}^{\mathrm{liq}}=-248000+50 T,{ }^{2} L_{\mathrm{Fe}, \mathrm{P}}^{\mathrm{liq}}=110000-57 T$ & this work \\
\hline & $\alpha$ & $(\mathrm{Fe}, \mathrm{P})_{1}$ & ${ }^{0} L_{\mathrm{Fe}, \mathrm{P}}^{\alpha}=-172000+4.7 T$ & 30 \\
\hline & $\gamma$ & $(\mathrm{Fe}, \mathrm{P})_{1}$ & ${ }^{0} L_{\mathrm{Fe}, \mathrm{P}}^{\gamma}=-156000+6 T$ & 30 \\
\hline & $\mathrm{Fe}_{3} \mathrm{P}$ & $(\mathrm{Fe})_{0.75}(\mathrm{P})_{0.25}$ & $G_{\mathrm{Fe}: \mathrm{P}}^{\mathrm{Fe}_{3} \mathrm{P}}=-49167.25125+157.35 T-27.725 T \ln T-0.0014625 T^{2}+134875 T^{-1}$ & 30 \\
\hline & $\mathrm{Fe}_{2} \mathrm{P}$ & $(\mathrm{Fe})_{0.667}(\mathrm{P})_{0.333}$ & $G_{\mathrm{Fe}: \mathrm{P}}^{\mathrm{Fe}_{2} \mathrm{P}}=-58880.7+121.48 T-22.2233 T \ln T-0.004783333 T^{2}$ & this work \\
\hline & $\mathrm{FeP}$ & $(\mathrm{Fe})_{0.5}(\mathrm{P})_{0.5}$ & $G_{\text {Fe:P }}^{\text {Fep }}=-74259.25+117.43 T-21.125 T \ln T-0.005225 T^{2}$ & this work \\
\hline & $\mathrm{FeP}_{2}$ & $(\mathrm{Fe})_{0.3333}(\mathrm{P})_{0.6667}$ & $G_{\mathrm{Fe}: \mathrm{P}}^{\mathrm{FeP}_{2}}=0.3333 G_{\mathrm{Fe}}^{\mathrm{bcc}}+0.6667 G_{\mathrm{p}}^{\text {white }}-76666+16.33 T$ & 30 \\
\hline & $\mathrm{FeP}_{4}$ & $(\mathrm{Fe})_{0.2}(\mathrm{P})_{0.8}$ & $G_{\mathrm{Fe}: \mathrm{P}}^{\mathrm{FeP}_{4}}=0.2 G_{\mathrm{Fe}}^{\mathrm{bcc}}+0.8 G_{\mathrm{P}}^{\text {white }}-62000+14.6 T$ & 30 \\
\hline \multirow[t]{2}{*}{ Al-P } & liq & $(\mathrm{Al}, \mathrm{P})_{1}$ & ${ }^{0} L_{\mathrm{Al}, \mathrm{P}}^{\mathrm{liq}}=86161-65.14 T$ & this work \\
\hline & $\mathrm{Al}$ & $(\mathrm{Al})_{0.5}(\mathrm{P})_{0.5}$ & $G_{\mathrm{Al}: \mathrm{P}}^{\mathrm{AIP}}=0.5 G_{\mathrm{Al}}^{\text {fcc }}+0.5 G_{\mathrm{P}}^{\text {white }}-74000+7.14 T$ & this work \\
\hline \multirow[t]{4}{*}{ Al-Fe-P } & liq & $(\mathrm{Al}, \mathrm{Fe}, \mathrm{P})_{1}$ & ${ }^{0} L_{\mathrm{Al}, \mathrm{Fe}, \mathrm{P}}^{\mathrm{liq}}=127280.1-120 T,{ }^{1} L_{\mathrm{Al}, \mathrm{Fe}, \mathrm{P}}^{\mathrm{liq}}=60000-120 T,{ }^{2} L_{\mathrm{Al}, \mathrm{Fe}, \mathrm{P}}^{\mathrm{liq}}=200000-170 T$ & this work \\
\hline & $\alpha$ & $(\mathrm{Al}, \mathrm{Fe}, \mathrm{P})_{1}$ & ${ }^{0} L_{\mathrm{Al}, \mathrm{Fe}, \mathrm{P}}^{\alpha}={ }^{1} L_{\mathrm{A}, \mathrm{Fe}, \mathrm{P}}^{\alpha}={ }^{2} L_{\mathrm{Al}, \mathrm{Fe}, \mathrm{P}}^{\alpha}=0$ & this work \\
\hline & $\mathrm{AlFe}$ & $(\mathrm{Al}, \mathrm{Fe}, \mathrm{P})_{0.5}(\mathrm{Al}, \mathrm{Fe}, \mathrm{P})_{0.5}$ & ${ }^{0} L_{\mathrm{Al}, \mathrm{Fe}, \mathrm{P}}^{\mathrm{AIFe}}={ }^{1} L_{\mathrm{Al}, \mathrm{Fe}, \mathrm{P}}^{\mathrm{AlFe}}={ }^{2} L_{\mathrm{Al}, \mathrm{Fe}, \mathrm{P}}^{\mathrm{AfFe}}=0$ & this work \\
\hline & $\gamma$ & $(\mathrm{Al}, \mathrm{Fe}, \mathrm{P})_{1}$ & ${ }^{0} L_{\mathrm{Al}, \mathrm{Fe}, \mathrm{P}}^{\gamma}={ }^{1} L_{\mathrm{Al}, \mathrm{Fe}, \mathrm{P}}^{\gamma}={ }^{2} L_{\mathrm{Al}, \mathrm{Fe}, \mathrm{P}}^{\gamma}=0$ & this work \\
\hline
\end{tabular}

analysis. The vertical sections of $w(\mathrm{P})=6 \%, 9 \%$ (mass fraction) and $w(\mathrm{Al})=10 \%, 25 \%$ were determined. The isothermal section at room temperature and the liquidus surface in the $\mathrm{Fe}-\mathrm{Fe}_{2} \mathrm{P}-$ $\mathrm{AlP}-\mathrm{Fe}_{50} \mathrm{Al}_{50}$ region were also investigated experimentally. There was found that the AlP- $\mathrm{Fe}_{2} \mathrm{P}$ and $\mathrm{AlP}-\mathrm{Fe}_{50} \mathrm{Al}_{50}$ sections are the quasi-binaries of the simple eutectic type. Kaneko et al..$^{32}$ investigated the phase relationships between phosphide-phase and iron-phase in the Al-Fe-P system by chemical and X-ray examinations and the obtained results agree with those reported by Vogel and Klose. ${ }^{31}$ Limited thermodynamic properties relevant to the Al-Fe-P system are reported. Yamada and Kato ${ }^{33,34}$ determined the activity interaction coefficients of phosphorus in the Fe-P- $i$ system at $1873 \mathrm{~K}$ using a Knudsen cell-mass spectrometer combination with the computation from the ratio of the intensities of $\mathrm{P}^{+}$and $\mathrm{Fe}^{+}$peaks, and $\varepsilon_{\mathrm{p}}^{\mathrm{Al}}=4.6 \pm 0.7$ was obtained. Based on the Miedema model and Toop equation Ding et al ${ }^{35}$ thermodynamically predicted the activity interaction coefficients between alloying elements and $\mathrm{P}$ in liquid $\mathrm{Fe}$ at $1873 \mathrm{~K}$ and the value of predicted $\varepsilon_{\mathrm{P}}^{\mathrm{Al}}$ is 8.78 , which is much larger than the measured mentioned above. On the basis of the above mentioned information, the phase equilibria in the Al-Fe-P ternary system were reviewed in references. ${ }^{36-38}$

Most recently, Wu et al. ${ }^{8}$ investigated the phase equilibrium in the Al-Fe-P system when the P content was below $20 \%$ (mass fraction) with SEM-EDS and XRD and released an isothermal section at $723 \mathrm{~K}$ of the Al-Fe-P system at low phosphorus contents. And up to now, no ternary phase has been found in this ternary system.

\section{Thermodynamic models}

The thermodynamic models adopted here for the phases of the Al-Fe-P system are summarized in Table 1 and briefly introduced below.

\subsection{Pure elements}

The Gibbs energy function $G_{i}^{\varphi}(T)={ }^{0} G_{i}^{\varphi}(T)-{ }^{0} H_{i}^{\mathrm{SER}}(298.15$ $\mathrm{K})$ for the element $i(i=\mathrm{Al}, \mathrm{Fe}, \mathrm{P})$ in the phase $\varphi$, which is also called lattice stability, is described by an equation of the following form:

$$
G_{i}^{\varphi}(T)=a+b T+c T \ln T+d T^{2}+e T^{3}+f T^{-1}+g T^{7}+h T^{-9}
$$

where ${ }^{0} H_{i}^{\mathrm{SER}}(298.15 \mathrm{~K})$ is the molar enthalpy of the element $i$ in its standard element reference (SER) state, bcc for Fe, fcc for $\mathrm{Al}$, and white form for $\mathrm{P} ; \mathrm{T}$ is the absolute temperature in K. Different sets of coefficients $a$ to $h$ used in different temperature ranges in Eq.(1) are cited from the SGTE database complied by Dinsdale. ${ }^{39}$ The lattice stability parameters for $\mathrm{Al}, \mathrm{Fe}$, and $\mathrm{P}$ used in this work are summarized in Table 2.

\subsection{Solution phases}

The solution phases are modeled by the substitutional solution model and their Gibbs energies are described by the following expression:

$$
G^{\varphi}(T)={ }^{\text {ref }} G^{\varphi}+{ }^{\text {id }} G^{\varphi}+{ }^{\text {ex }} G^{\varphi}
$$

where the three terms assume different forms according to the nature of the phase. Substitutional solutions are represented by only one sublattice where all the atoms mix randomly. In the binary case $(A, B)_{1}$, the three contributions to the Gibbs energy are: 
${ }^{\mathrm{ref}} G^{\varphi}=x_{\mathrm{A}} G_{\mathrm{A}}^{\varphi}+x_{\mathrm{B}} G_{\mathrm{B}}^{\varphi}$

${ }^{\text {id }} G^{\varphi}=R T\left(x_{\mathrm{A}} \ln x_{\mathrm{A}}+x_{\mathrm{B}} \ln x_{\mathrm{B}}\right)$

${ }^{\text {ex }- \text { bin }} G^{\varphi}=x_{\mathrm{A}} x_{\mathrm{B}} \sum L_{\mathrm{A}, \mathrm{B}}^{\varphi}(T)\left(x_{\mathrm{A}}-x_{\mathrm{B}}\right)^{v}$

where $G_{\mathrm{A}}^{\varphi}$ and $G_{\mathrm{B}}^{\varphi}$ are the Gibbs energies of the pure elements
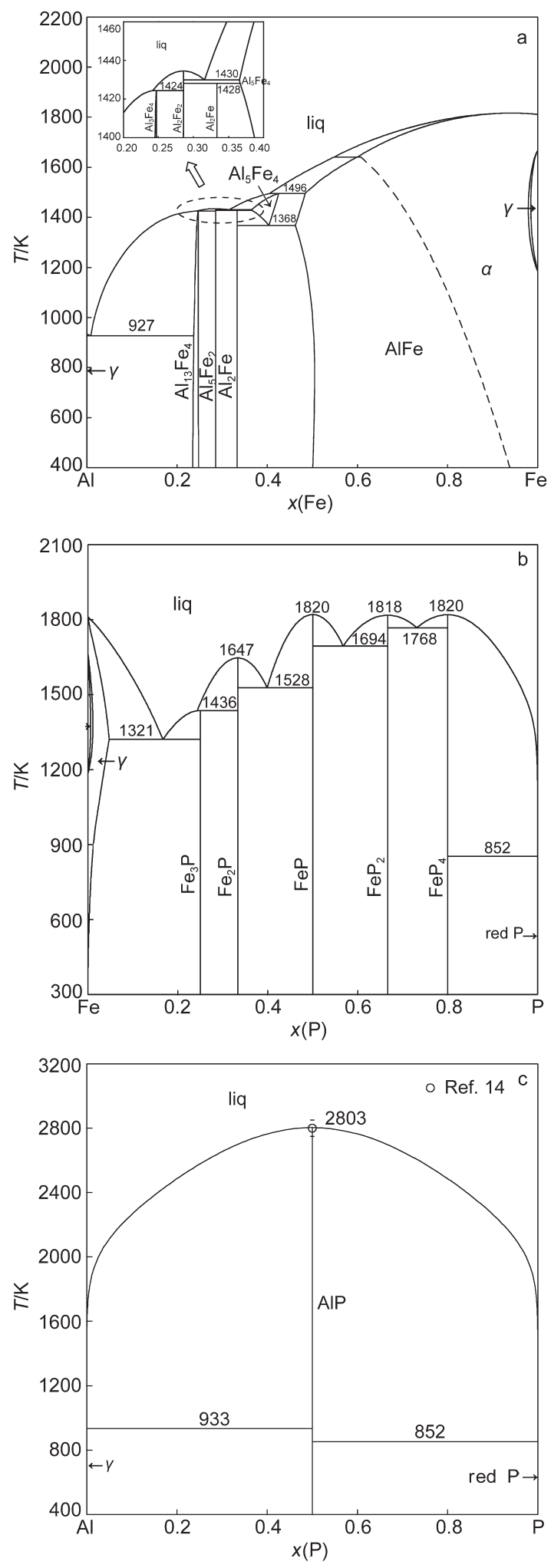

Fig.1 Calculated binary phase diagrams

(a) Al-Fe system, ${ }^{22}$ (b) Fe-P system, ${ }^{30}$ (c) Al-P system in this work in the $\varphi$ structure and the $L_{\mathrm{A}, \mathrm{B}}^{\varphi}$ functions have the form:

$$
L_{\mathrm{A}, \mathrm{B}}^{\varphi}=a_{\mathrm{A}, \mathrm{B}}^{\varphi}+b_{\mathrm{A}, \mathrm{B}}^{\varphi} T+c_{\mathrm{A}, \mathrm{B}}^{\varphi} T \ln T
$$

where $a_{\mathrm{A}, \mathrm{B}}^{\varphi}, b_{\mathrm{A}, \mathrm{B}}^{\varphi}$, and $c_{\mathrm{A}, \mathrm{B}}^{\varphi}$ are model parameters to be optimized. In most cases, only the first two terms are used according to the temperature dependence on the experimental data.

In the case of ternary solutions, the expressions of ${ }^{\text {ref }} G^{\varphi}$ and ${ }^{\text {id }} G^{\varphi}$ are easily derived from the binary ones. As for the excess Gibbs energy, it is obtained by combing the binary excess Gibbs energies according to the Muggianu extrapolation formu$1 \mathrm{a}^{40}$ and adding a ternary excess term:

$$
{ }^{\text {ex }- \text { ter }} G^{\varphi}=x_{\mathrm{A}} x_{\mathrm{B}} x_{\mathrm{C}}\left(x_{\mathrm{A}}^{0} L_{\mathrm{A}, \mathrm{B}, \mathrm{C}}^{\varphi}(T)+x_{\mathrm{B}}^{1} L_{\mathrm{A}, \mathrm{B}, \mathrm{C}}^{\varphi}(T)+x_{\mathrm{C}}^{2} L_{\mathrm{A}, \mathrm{B}, \mathrm{C}}^{\varphi}(T)\right)
$$

and the $L$ functions have the form shown in Eq.(4).

This model has been adopted for the following phases: liquid, $\alpha, \gamma$, and $\mathrm{Al}_{5} \mathrm{Fe}_{4}$ (see Table 1).

\subsection{Ordered/disordered phases}

The ordered AlFe phase with bcc_B2 structure is modeled as $(\mathrm{Al}, \mathrm{Fe})_{0.5}(\mathrm{Al}, \mathrm{Fe})_{0.5}$ in the $\mathrm{Al}-\mathrm{Fe}$ system. ${ }^{22}$ In order to represent the Gibbs energy of the ordered/disordered transitions using a single function, the disordered $\alpha$-Fe phase with bcc_A2 structure is described by $(\mathrm{Al}, \mathrm{Fe})_{1}$. Ansara et al. ${ }^{41,42}$ have derived an equation which allows the thermodynamic properties of the disordered phase to be evaluated independently. This is done by resolving the Gibbs energy into three terms as following:

$$
G_{\mathrm{m}}=G_{\mathrm{m}}^{\alpha-\mathrm{Fe}}\left(x_{i}\right)+G_{\mathrm{m}}^{\mathrm{AlFe}}\left(y_{i}^{\prime}, y_{i}^{\prime \prime}\right)-G_{\mathrm{m}}^{\mathrm{AIFe}}\left(x_{i}\right)
$$

in which $y_{i}^{\prime}$ is the site fraction of $i(i=\mathrm{Al}$ and $\mathrm{Fe})$ in the first sublattice, and $y_{i}^{\prime \prime}$ in the second one. $G_{\mathrm{m}}^{\alpha-\mathrm{Fe}}\left(x_{i}\right)$ is the Gibbs energy of the disordered $\alpha-\mathrm{Fe}$ phase. The second term $G_{\mathrm{m}}^{\mathrm{Alfe}}\left(y_{i}{ }^{\prime}, y_{i}{ }^{\prime \prime}\right)$ is described by the sublattice model and implicitly contains a contribution from the disordered state. The last term $G_{\mathrm{m}}^{\mathrm{AfF}}\left(x_{i}\right)$ represents the contribution from the disordered state to the ordered one. When the site fractions are equal, i.e. $y_{i}{ }^{\prime}=y_{i}{ }^{\prime \prime}$, the last two terms cancel each other. The ordered AlFe phase with bcc_B2 structure and the disordered $\alpha$-Fe phase with bcc_A2 structure are modeled as $(\mathrm{Al}, \mathrm{Fe}, \mathrm{P})_{0.5}(\mathrm{Al}, \mathrm{Fe}, \mathrm{P})_{0.5}$ and $(\mathrm{Al}, \mathrm{Fe}, \mathrm{P})_{1}$ in the $\mathrm{Al}-\mathrm{Fe}-\mathrm{P}$ ternary system, respectively. Due to lack of the experimental information on the ordered/disordered transition in the Al-Fe-P ternary system the ternary interaction parameters are assumed to be zero.

\subsection{Intermetallic compounds}

Stoichiometric compounds are represented with as many sublattices as the number of component elements, with only one atom type in each sublattice. In the binary case the model is $(\mathrm{A})_{u}(\mathrm{~B})_{1-u}$ and the Gibbs energies are given by

$$
G^{\varphi}=u G_{\mathrm{A}}^{\mathrm{SER}}+(1-u) G_{\mathrm{B}}^{\mathrm{SER}}+\Delta G_{\mathrm{f}}^{\mathrm{A}_{u} \mathrm{~B}_{1-u}}
$$

where $\Delta G_{f}^{A_{u} B_{1-u}}$ is the Gibbs energy of formation of the phase referred to the component element in the SER state and also has the form shown in Eq.(4).

The Eq.(7) was adopted to describe the Gibbs energies of the stoichiometric compounds that were lack of heat capacity data: $\mathrm{Al}_{5} \mathrm{Fe}_{2}, \mathrm{Al}_{2} \mathrm{Fe}, \mathrm{FeP}_{2}, \mathrm{FeP}_{4}$, and AlP (see Table 1).

For $\mathrm{Fe}_{3} \mathrm{P}, \mathrm{Fe}_{2} \mathrm{P}$, and $\mathrm{FeP}$ phases, the heat capacity data are available in a wide temperature range ${ }^{29}$ and their Gibbs energies are given by 
Table 2 Lattice stability parameters used in the present optimization ${ }^{39}$

\begin{tabular}{|c|c|c|c|c|}
\hline Element & Phase & & Lattice stability parameters $/\left(\mathrm{J} \cdot \mathrm{mol}^{-1}\right)$ & $T / \mathrm{K}$ \\
\hline \multirow[t]{9}{*}{$\mathrm{Al}$} & liq & ${ }^{0} G_{\mathrm{Al}}^{\text {liq }}-{ }^{0} H_{\mathrm{Al}}^{\mathrm{fec}}$ & $=3028.879+125.251171 T-24.3671976 T \ln T-0.001884662 \times T^{2}-8.77664 \times 10^{-7} T^{3}+74092 T^{-1}+7.9337 \times 10^{-20} T^{7}$ & $298.15-700$ \\
\hline & & & $=-271.21+211.206579 T-38.5844296 T \ln T+0.018531982 T^{2}-5.764227 \times 10^{-6} T^{3}+74092 T^{-1}+7.9337 \times 10^{-20} T^{7}$ & $700-933.4$ \\
\hline & & & $=-795.996+177.430178 T-31.748192 T \ln T$ & $933.4-2900$ \\
\hline & fcc & ${ }^{0} G_{\mathrm{Al}}^{\mathrm{fcc}}-{ }^{0} H_{\mathrm{Al}}^{\mathrm{fcc}}$ & $=-7976.15+137.093038 T-24.3671976 T \ln T-0.001884662 T^{2}-8.77664 \times 10^{-7} T^{3}+74092 T^{-1}$ & $298.15-700$ \\
\hline & & & $=-11276.24+223.048446 T-38.5844296 T \ln T+0.018531982 T^{2}-5.764227 \times 10^{-6} T^{3}+74092 T^{-1}$ & $700-933.4$ \\
\hline & & & $=-11278.378+188.684153 T-31.748192 T \ln T-1.230524 \times 10^{28} T^{-9}$ & $933.4-2900$ \\
\hline & bcc & ${ }^{0} G_{\mathrm{Al}}^{\mathrm{bcc}}-{ }^{0} H_{\mathrm{Al}}^{\mathrm{bcc}}$ & $=2106.85+132.280038 T-24.3671976 T \ln T-0.001884662 T^{2}-8.77664 \times 10^{-7} T^{3}+74092 T^{-1}$ & $298.15-700$ \\
\hline & & & $=-1193.24+218.235446 T-38.5844296 T \ln T+0.018531982 T^{2}-5.764227 \times 10^{-6} T^{3}+74092 T^{-1}$ & $700-933.4$ \\
\hline & & & $=-1195.378+183.871153 T-31.748192 T \ln T-1.230524 \times 10^{28} T^{-9}$ & $933.4-2900$ \\
\hline \multirow[t]{8}{*}{$\mathrm{Fe}$} & liq & ${ }^{0} G_{\mathrm{Fe}}^{\mathrm{liq}}-{ }^{0} H_{\mathrm{Fe}}^{\mathrm{bcc}}$ & $=13265.87+117.57557 T-23.5143 T \ln T-0.00439752 T^{2}-5.8927 \times 10^{-8} T^{3}+77359 T^{-1}-3.67516 \times 10^{-21} T^{7}$ & $298.15-1811$ \\
\hline & & & $=-10839.7+291.302 T-46 T \ln T$ & $1811-6000$ \\
\hline & bcc & ${ }^{0} G_{\mathrm{Fe}}^{\mathrm{bcc}}-{ }^{0} H_{\mathrm{Fe}}^{\mathrm{bcc}}$ & $=1225.7+124.134 T-23.5143 T \ln T-0.00439752 T^{2}-5.8927 \times 10^{-8} T^{3}+77359 T^{-1}$ & $298.1-1811$ \\
\hline & & & $=-25383.581+299.31255 T-46 T \ln T+2.29603 \times 1031 T^{-9}$ & $1811-6000$ \\
\hline & & & $\left(T_{\mathrm{c} \mathrm{Fe}}^{a}=1043 \mathrm{~K}, \quad \beta_{\mathrm{Fe}}^{a}=2.22 \mathrm{~J} \cdot \mathrm{K}^{-1}\right)$ & $298.15-6000$ \\
\hline & fcc & ${ }^{0} G_{\mathrm{Fe}}^{\mathrm{fcc}}-{ }^{0} H_{\mathrm{Fe}}^{\mathrm{fcc}}$ & $=-236.7+132.416 T-24.6643 T \ln T-0.00375752 T^{2}-5.8927 \times 10^{-8} T^{3}+77359 T^{-1}$ & $298.15-1811$ \\
\hline & & & $=-27098.266+300.25256 T-46 T \ln T+2.78854 \times 10^{31} T^{-9}$ & $1811-6000$ \\
\hline & & & $\left(T_{\mathrm{cFe}}^{\gamma}=-201 \mathrm{~K}, \quad \beta_{\mathrm{Fe}}^{\gamma}=-2.1 \mathrm{~J} \cdot \mathrm{K}^{-1}\right)$ & $298.15-6000$ \\
\hline \multirow[t]{11}{*}{$\mathrm{P}$} & liq & ${ }^{0} G_{\mathrm{p}}^{\text {liq }}-{ }^{0} H_{\mathrm{p}}^{\text {white }}$ & $=-26316.111+434.943931 T-70.7440584 T \ln T-0.002898936 T^{2}+3.9049341 \times 10^{-5} T^{3}+1141.47 T^{-1}$ & $275-342.3$ \\
\hline & & & $=-7232.449+133.304873 T-26.326 T \ln T$ & $342.3-6000$ \\
\hline & bcc & ${ }^{0} G_{\mathrm{p}}^{\mathrm{bcc}}-{ }^{0} G_{\mathrm{p}}^{\mathrm{red}}$ & $=44769-13.26 T$ & $298.15-6000$ \\
\hline & fcc & ${ }^{0} G_{\mathrm{p}}^{\text {fcc }}-{ }^{0} G_{\mathrm{P}}^{\text {red }}$ & $=36819-13.138 T$ & $298.15-6000$ \\
\hline & red & ${ }^{0} G_{\mathrm{P}}^{\text {red }}-{ }^{0} H_{\mathrm{p}}^{\text {white }}$ & $=-25976.559+148.685002 T-25.55 T \ln T+0.0034121 T^{2}-2.418867 \times 10^{-6} T^{3}+160095 T^{-1}$ & $275-500$ \\
\hline & & & $=-21723.721+77.684737 T-14.368 T \ln T-0.00957685 T^{2}+3.93917 \times 10^{-7} T^{3}-141375 T^{-1}$ & $500-852.35$ \\
\hline & & & $=-119408.413+1026.04262 T-149.449556 T \ln T+0.067272364 T^{2}-6.651929 \times 10^{-6} T^{3}+1249543 T^{-1}$ & $852.35-1500$ \\
\hline & & & $=-24524.119+153.852181 T-26.326 T \ln T$ & $1500-3000$ \\
\hline & white & ${ }^{0} G_{\mathrm{p}}^{\text {white }}-{ }^{0} H_{\mathrm{p}}^{\text {white }}$ & $=-43821.799+1026.70689 T-178.426 T \ln T+0.290708 T^{2}-1.04022667 \times 10^{-4} T^{3}+1632695 T^{-1}$ & $250-317.3$ \\
\hline & & & $=-9587.448+152.354487 T-28.7335301 T \ln T+0.001715669 T^{2}-2.2829 \times 10^{-7} T^{3}+172966 T^{-1}$ & $317.3-900$ \\
\hline & & & $=-8093.075+135.889831 T-26.3267 \ln T$ & $900-3000$ \\
\hline
\end{tabular}

$T_{\mathrm{c}}$ : Curie temperature, $\beta$ : magnetic moment

$$
G^{\varphi}=\Delta_{\mathrm{f}} H_{298 \mathrm{~K}}+\int_{298 \mathrm{~K}}^{T} C_{p} \mathrm{~d} T-T\left[S_{298 \mathrm{~K}}+\int_{298 \mathrm{~K}}^{T}\left(C_{p} / T\right) \mathrm{d} T\right]
$$

where $\Delta_{\mathrm{f}} H_{298 \mathrm{~K}}$ and $S_{298 \mathrm{~K}}$ are the enthalpy of formation and the entropy at $298 \mathrm{~K}$, and $C_{p}$ is the heat capacities at constant pressure.

In Seierstein's study, ${ }^{22}$ non- stoichiometric compound, $\mathrm{Al}_{13} \mathrm{Fe}_{4}$, was modeled with three sublattices: $(\mathrm{Al})_{0.6275}(\mathrm{Fe})_{0.235}(\mathrm{Al}, \mathrm{Va})_{0.1375}$ in order to account for its binary solubility range. The Gibbs energy is given by

$$
\begin{aligned}
G^{\mathrm{Al}_{13} \mathrm{Fe}_{4}}= & y_{\mathrm{Al}}^{\prime \prime \prime} G_{\mathrm{Al}: \mathrm{Fe}: \mathrm{Al}}^{\mathrm{Al}_{1} \mathrm{Fe}_{4}}+y_{\mathrm{Va}^{\prime \prime \prime}}^{\prime \prime \prime} G_{\mathrm{Al}: \mathrm{Fe}: \mathrm{Va}}^{\mathrm{Al}_{1} \mathrm{Fe}_{4}}+ \\
& 0.1375 R T\left(y_{\mathrm{Al}}^{\prime \prime \prime} \ln y_{\mathrm{Al}}^{\prime \prime \prime}+y_{\mathrm{Va}}^{\prime \prime \prime} \ln y_{\mathrm{Va}}^{\prime \prime \prime}\right)
\end{aligned}
$$

where the superscript "' denotes the third sublattice of the presented model, $y_{i}^{\prime \prime \prime}$ is the site fraction of $i$ in the third sublattice, Va is the vacancy in the third sublattice. $G_{\mathrm{Al}: \mathrm{Fe}: \mathrm{Al}}^{\mathrm{Al}_{1} \mathrm{Fe}_{4}}$ and $G_{\mathrm{Al}: \mathrm{Fe}: \mathrm{Va}}^{\mathrm{Al}_{13} \mathrm{Fe}_{4}}$ are the Gibbs energy of the two end members $(\mathrm{Al})_{0.6275}(\mathrm{Fe})_{0.235}(\mathrm{Al})_{0.1375}$ and $(\mathrm{Al})_{0.6275}(\mathrm{Fe})_{0.235}(\mathrm{Va})_{0.1375}$.

No ternary intermetallic compounds have been reported in previous study and all binary intermetallic phases were treated to have zero ternary solubility in the Al-Fe-P system in present work.

\section{Optimization results and discussion}

The binary and ternary interaction parameters have been optimized using the PARROT module included in the ThermoCalc software package. ${ }^{9}$ The phase diagram data and experimental thermodynamic information were used as the input to the program. Each datum value was given a certain weight by our personal evaluation of the datum source and considering the consistency between the phase diagram and the thermodynamic properties. The interaction parameters have been evaluated by trial and error method during the course of the optimization until most of the selected experimental information is reproduced within the expected uncertainty limits. As a result, a complete list of the thermodynamic parameters describing the Al-Fe-P system is summarized in Table 1. Computed phase equilibria are compared to the selected experimental information reviewed in Sections 2.1 and 2.3. And a brief discussion is given as below.

\subsection{Al-P binary system}

The calculated phase diagram of Al-P system is shown in Fig.1(c). The evaluated melting point of AlP is $2803 \mathrm{~K}$, which agrees well with the experimental value $(2803 \pm 50) \mathrm{K} .{ }^{14}$ As mentioned in Section 2.1, there are large differences among the experimental values of enthalpy formation of AlP determined by 
different researchers. The calculated $\Delta_{\mathrm{f}} H_{298 \mathrm{~K}}(\mathrm{AlP})=-74.0 \mathrm{~kJ} \cdot$ $\mathrm{mol}^{-1} \cdot$ atom $^{-1}$, is close to the value measured by Wang and Zaheervuddin. ${ }^{16}$

\subsection{Al-Fe-P ternary system}

By using the present optimized parameters of the Al-P system along with the reported parameters of the $\mathrm{Al}-\mathrm{Fe}^{22}$ and $\mathrm{Fe}-$ $\mathrm{P}^{30}$ systems, and based on the vertical section and isothermal section diagram information, the Al-Fe-P ternary system is fur-

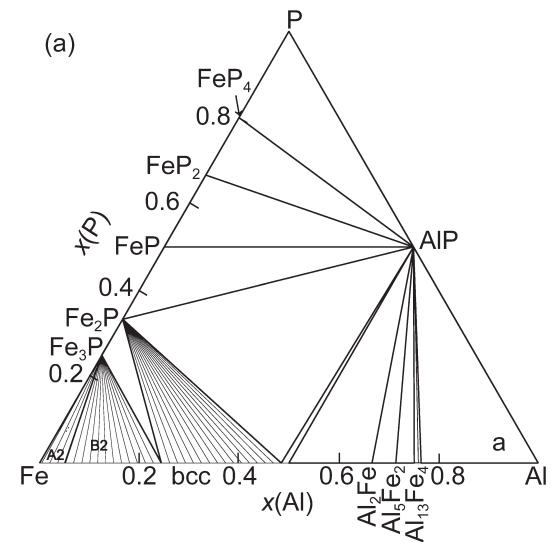

ther optimized. The parameters of the Al-Fe and Fe-P system were slightly modified in order to fit the experimental data better.

The experimental and calculated isothermal section diagrams at room temperature are shown in Fig.2. It is easy to see that most of the phase relations have been well reproduced. The representative calculated vertical section diagrams with experimental data are illustrated in Fig.3. Although there is, in

Fig.2 (a) Isothermal section diagram of the Al-Fe-P system at room temperature determined by Vogel and Klose ${ }^{31}$ and redrawn by Schmid-Fetzer and Tomashik $^{38}$ and (b) calculated isothermal section diagram at room temperature in this work
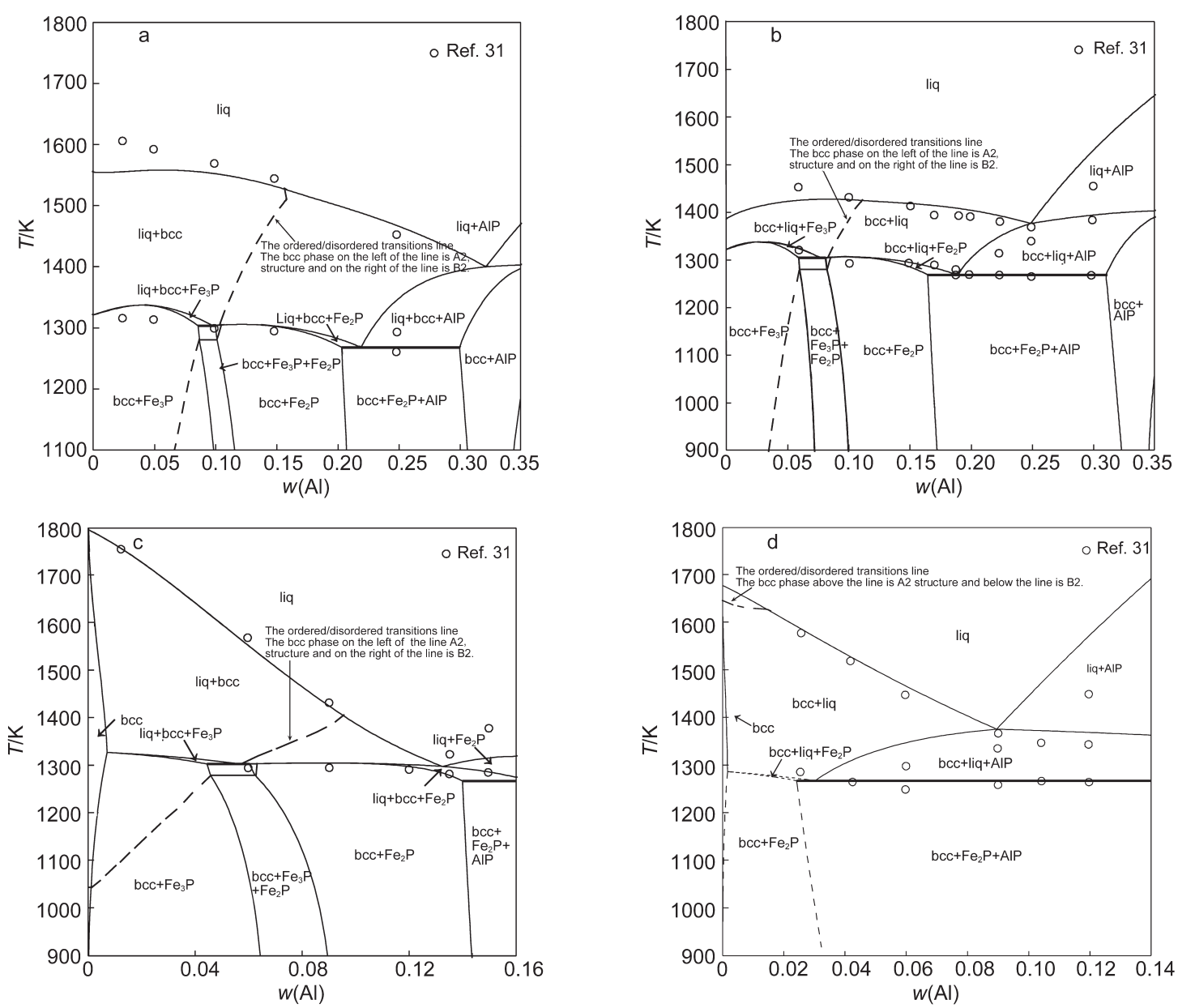

Fig.3 Calculated vertical section diagrams compared with the experimental data ${ }^{31}$

(a) $w(\mathrm{P})=6 \%$, (b) $w(\mathrm{P})=9 \%$, (c) $w(\mathrm{Al})=10 \%,(\mathrm{~d}) w(\mathrm{Al})=25 \%$ 
general, a satisfactory agreement between the experimental data reported by Vogel and Klose ${ }^{31}$ for the phase diagram, some differences still exist, e.g. a relative discrepancy on the liquidus line between the calculated and the experimental data was observed. Actually, great care has been taken to reduce these discrepancies in our assessment, but it was found that it is difficult to fit these experimental data very well. It is still necessary to get more new experimental data to solve this problem. Additionally, some of the equilibria with respect to the bcc phase are inconsistent with the measured vertical sections by Vogel and Klose, ${ }^{31}$ e.g. in our assessment, bcc phase is respectively in equilibrium with $\mathrm{Fe}_{2} \mathrm{P}$ and liq $+\mathrm{Fe}_{2} \mathrm{P}$ in the dashed regions, as shown in Fig.3(d), rather than AlP and liq + AlP reported by Vogel and Klose. ${ }^{31}$

It was worthy to point out that we calculated the isothermal section diagram of the Al-Fe-P system at $723 \mathrm{~K}$ and compared with the latest experimental data, ${ }^{8}$ which was published after the present assessment had been finished, and a good agree-

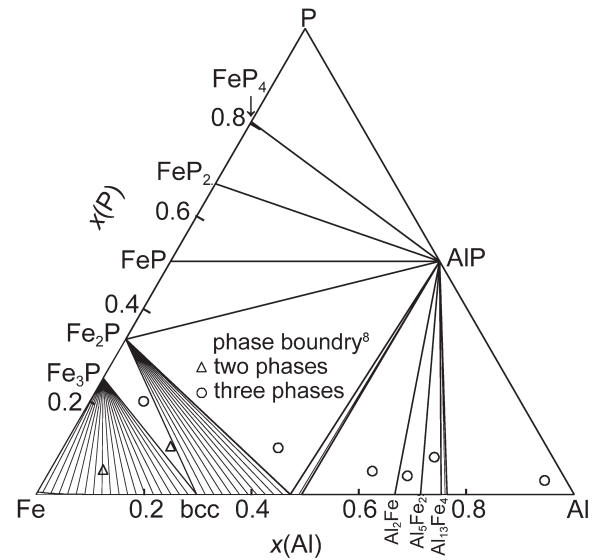

Fig.4 Calculated isothermal section diagram of the Al-Fe-P system at $723 \mathrm{~K}$ compared with the experimental data ${ }^{8}$

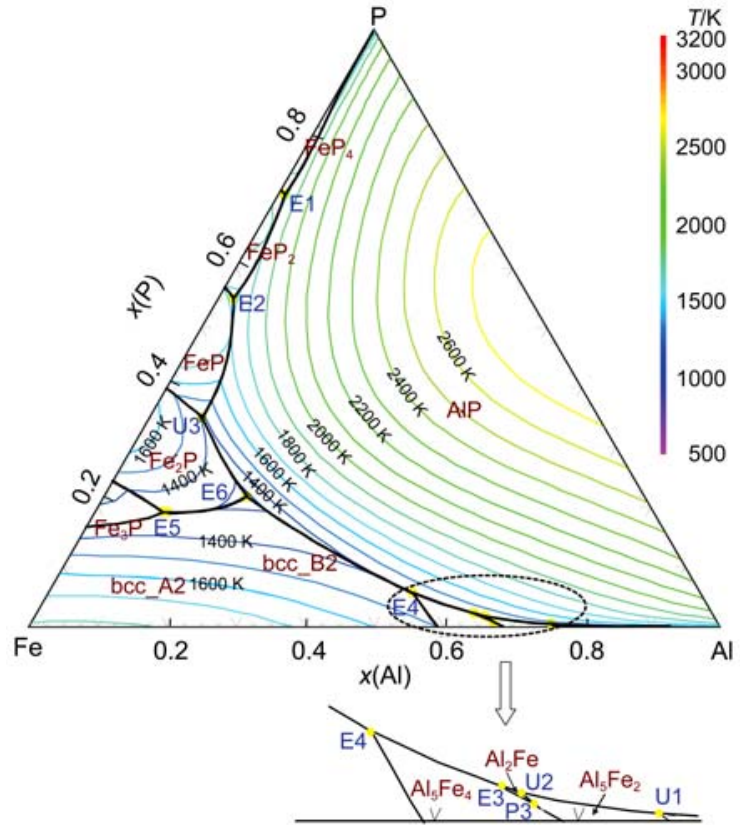

Fig.5 Calculated liquidus projection of the Al-Fe-P system
Table 3 Present calculated values for the invariant reactions in the Al-Fe-P system with the experimental data ${ }^{31}$

\begin{tabular}{|c|c|c|c|c|c|}
\hline Reaction & $T / \mathrm{K}$ & Type & $x($ liq, $\mathrm{Al})$ & $x($ liq, $\mathrm{Fe})$ & Ref. \\
\hline $\mathrm{liq} \rightarrow \mathrm{AlP}+\mathrm{FeP}_{2}+\mathrm{FeP}_{4}$ & 1759 & E1 & 0.009 & 0.267 & this work \\
\hline $\mathrm{liq} \rightarrow \mathrm{FeP}+\mathrm{AlP}+\mathrm{FeP}_{2}$ & 1663 & E2 & 0.021 & 0.428 & this work \\
\hline $\mathrm{liq}+\mathrm{Al}_{5} \mathrm{Fe}_{4}+\mathrm{Al}_{5} \mathrm{Fe}_{2} \rightarrow \mathrm{Al}_{2} \mathrm{Fe}$ & 1426 & P3 & 0.675 & 0.321 & this work \\
\hline $\mathrm{liq}+\mathrm{Al}_{5} \mathrm{Fe}_{2} \rightarrow \mathrm{AlP}+\mathrm{Al}_{13} \mathrm{Fe}_{4}$ & 1422 & U1 & 0.751 & 0.245 & this work \\
\hline $\mathrm{liq}+\mathrm{Al}_{5} \mathrm{Fe}_{2} \rightarrow \mathrm{Al}_{2} \mathrm{Fe}+\mathrm{AlP}$ & 1417 & $\mathrm{U} 2$ & 0.651 & 0.331 & this work \\
\hline $\mathrm{liq} \rightarrow \mathrm{AlP}+\mathrm{Al}_{5} \mathrm{Fe}_{4}+\mathrm{Al}_{2} \mathrm{Fe}$ & 1414 & E3 & 0.628 & 0.349 & this work \\
\hline $\mathrm{liq} \rightarrow \mathrm{AlFe}+\mathrm{Al}_{5} \mathrm{Fe}_{4}+\mathrm{AlP}$ & 1403 & E4 & 0.532 & 0.413 & this work \\
\hline $\mathrm{liq}+\mathrm{FeP} \rightarrow \mathrm{Fe}_{2} \mathrm{P}+\mathrm{AlP}$ & 1383 & $\mathrm{U} 3$ & 0.076 & 0.574 & this work \\
\hline \multirow[t]{2}{*}{$\mathrm{liq} \rightarrow \alpha+\mathrm{Fe}_{3} \mathrm{P}+\mathrm{Fe}_{2} \mathrm{P}$} & 1303 & E5 & 0.099 & 0.710 & this work \\
\hline & 1298 & & 0.140 & 0.680 & 31 \\
\hline \multirow[t]{2}{*}{$\mathrm{liq} \rightarrow \mathrm{AlFe}+\mathrm{Fe}_{2} \mathrm{P}+\mathrm{AlP}$} & 1268 & E6 & 0.206 & 0.575 & this work \\
\hline & 1268 & & 0.275 & 0.556 & 31 \\
\hline $\mathrm{liq} \rightarrow \gamma+\mathrm{Al}_{13} \mathrm{Fe}_{4}+\mathrm{AlP}$ & 927 & E7 & 0.991 & 0.009 & this work \\
\hline $\mathrm{liq} \rightarrow \mathrm{FeP}_{4}+\mathrm{P}+\mathrm{AlP}$ & 852 & E8 & $\sim 0$ & $\sim 0$ & this work \\
\hline
\end{tabular}

ment between them was obtained, as shown in Fig.4. It proved that the thermodynamic parameters gained in our optimization are reliable.

Taking into account the available information on the binary and ternary systems, the complete liquidus projection for the whole Al-Fe-P system are illustrated in Fig.5. The calculated and experimental invariant temperatures and the corresponding compositions for the various invariant reactions are summarized in Table 3. Although the temperatures are generally in good agreement with the experimental values, there are still some differences in the compositions. Invariant reactions E7 and E8 are very near to the binary subsystems, so these two invariant reactions cannot be visible in Fig.5. Necessary experiments are also needed to validate the liquidus projection in the Al-Fe-P system.

\section{Explanation on the glass-forming ability}

The driving force (DF) criterion ${ }^{5,6}$ is based on the assumption that the phase having the highest driving force is most like-

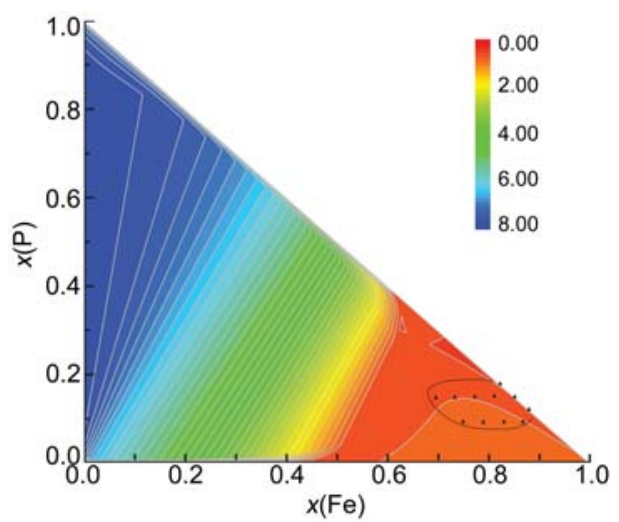

Fig.6 Calculated driving force (DF) surface projection at $973 \mathrm{~K}$ superimposed with iso-DF lines and the experimental glass compositions denoted by Inoue ${ }^{4}$

The values of the DF shown in the color bar have been divided by $R T$, and thus are dimensionless. 
ly to form first. Considering that the formation of an amorphous phase would be favored when the nucleation and growth of crystalline phases are retarded, then the composition with the highest glass-forming ability can be the one with the lowest driving force of formation of crystalline phases. In order to analyze the composition dependency of the glass-forming ability, the initial crystallization driving force, which can be regarded as a representation of the nucleation ability of the crystalline phases, was employed in this work. The initial driving forces of all crystalline phases under every specified liquid composition at $973 \mathrm{~K}$ were first calculated and then the maximal values under each composition were chosen to construct the DF surface projection, as shown in Fig.6. Iso-DF lines and the experimental glass compositions are superimposed on it. All the experimental data are in the region where the driving forces are lower than 0.9. This is in accordance with the driving force criterion: alloys having lower driving forces possess higher glassforming abilities. This proves that the driving force criterion can be used as an index to predict the composition field most likely having the best glass-forming ability before any experiments.

\section{Conclusions}

Based on the available experimental information on the Al-P and the Al-Fe-P systems as well as the published assessment of the Al-Fe and the Fe-P binary systems, a critical assessment of the Al-P binary and the Al-Fe-P ternary system was carried out and a consistent thermodynamic description for describing all the phases in the Al-Fe-P system was obtained. The phase diagrams of the Al-Fe-P system over the entire composition range, including the vertical sections for $w(\mathrm{P})=6 \%, 9 \%$, and $w(\mathrm{Al})=$ $10 \%, 25 \%$, the isothermal section at room temperature as well as the liquidus projection was constructed from present thermodynamic calculation. Most reported compositions of amorphous phase lie in the regions with low initial driving forces for the crystalline phases, which soundly proves the reasonability and reliability of the present thermodynamic description.

\section{References}

(1) Fukamichi, K.; Kikuchi, M.; Hiroyoshi, H.; Masumoto, T. Anomalous Thermal Expansion, $\Delta E$ Effect, Invar and Elinvar Characteristics of Some Fe-based Amorphous Alloys. In Rapidly Quenched Metals III; Cantor, B. Ed.; The Metals Society: London, 1978.

(2) Masumoto, T.; Hashimoto, K.; Naka, M. Corrosion Behavior of Amorphous Metals. In Rapidly Quenched Metals III; Cantor, B. Ed.; The Metals Society: London, 1978.

(3) Yokoyama, A.; Komiyama, H.; Inoue, H.; Masumoto, T.; Kimura, H. M. Scripta Met. 1981, 15, 365.

(4) Inoue, A.; Kitamura, A.; Masumoto, T. Mater. Sci. 1983, 18, 753. doi: 10.1007/BF00745573

(5) Kim, D.; Lee, B. J.; Kim, N. J. Intermetallics 2004, 12, 1103. doi: 10.1016/j.intermet.2004.04.001

(6) Kim, D.; Lee, B. J.; Kim, N. J. Scripta Mater. 2005, 52, 969. doi: 10.1016/j.scriptamat.2005.01.038

(7) Bo, H.; Wang, J.; Jin, S.; Qi, H. Y.; Yuan, X. L.; Liu, L. B.; Jin, Z. P. Intermetallics 2010, 18, 2322. doi: 10.1016/j. intermet.2010.08.002

(8) Wu, C. J.; Huang, W. M.; Su, X. P.; Peng, H. P.; Wang, J. H.; Liu, Y. CALPHAD 2012, 38, 1. doi: 10.1016/j. calphad.2012.03.005

(9) Sundman, B.; Jansson, B.; Andersson, J. O. CALPHAD 1985, 9 , 153. doi: 10.1016/0364-5916(85)90021-5

(10) White, W. E.; Bushey, A. H. J. Am. Chem. Soc. 1944, 66, 1666. doi: $10.1021 / \mathrm{ja} 01238 \mathrm{a} 018$

(11) Panish, M. B.; Ilegems, M. Prog. Solid State Chem. 1972, 7, 39. doi: 10.1016/0079-6786(72)90004-0

(12) Ilegems, M.; Panish, M. B. Crys. Growth 1973, 20, 77. doi: 10.1016/0022-0248(73)90117-6

(13) Tu, H.; Yin, F. C.; Su, X. P.; Liu, Y.; Wang, X. M. CALPHAD 2009, 33, 755. doi: 10.1016/j.calphad.2009.10.003

(14) Kischio, W. Inorg. Nucl. Chem. 1965, 27, 750. doi: 10.1016/ 0022-1902(65)80287-1

(15) Czochrallski, J. Z. Metallkd. 1923, 15, 273.

(16) Wang, C. C.; Zaheervuddin, M. Inorg. Nucl. Chem. 1963, 25, 326. doi: 10.1016/0022-1902(63)80071-8

(17) de Maria, G.; Gingerich, K. A.; Piacente, V. Chem. Phys. 1968, 49, 4705 .

(18) McAlister, A. J. Alloy Phase Diagrams 1985, 6 (3), 222. doi: 10.1007/BF02880402

(19) Martosudirdjo, S.; Pratt, J. N. Thermochim. Acta 1974, 10, 23. doi: 10.1016/0040-6031(74)85019-7

(20) Kaufman, L.; Nesor, H. CALPHAD 1978, 2, 325. doi: 10.1016/ 0364-5916(78)90020-2

(21) Saunders, N.; Rivlin, V. G. Z. Metallkd. 1987, 78, 795.

(22) Seierstein, M. The Al-Fe System. In COST 507, Thermochemical Database for Light Metal Alloys; Ansara, I., Dinsdale, A. T., Rand, M. H. Eds.; Office for Official Publications of the European Communities: Luxembourg, 1998.

(23) Zhang, L. J.; Du, Y. CALPHAD 2007, 31, 529. doi: 10.1016/j. calphad.2007.03.003

(24) Du, Y.; Schuster, J. C.; Liu, Z. K.; Hu, R. X.; Nash, P.; Sun, W. H.; Zhang, W. W.; Wang, J.; Zhang, L. J.; Tang, C. Y.; Zhu, Z. J.; Liu, S. H.; Ouyang, Y. F.; Zhang, W. Q.; Krendelsberger, N. Intermetallics 2008, 16 (4), 554. doi: 10.1016/j. intermet.2008.01.003

(25) Guo, C. P.; Du, Z. M.; Li, C. R.; Zhang, B. L.; Tao, M. CALPHAD 2008, 32, 637. doi: 10.1016/j.calphad.2008.08.007

(26) Okamoto, H. Bull. Alloy Phase Diagrams 1990, 11, 404. doi: 10.1007/BF02843320

(27) Ohtani, H.; Hanaya, N.; Hasebe, M.; Teraoka, S.; Abe, M. CALPHAD 2006, 30, 147. doi: 10.1016/j.calphad.2005.09.006

(28) Tokunaga, T.; Hanaya, N.; Ohtani, H.; Hasebe, M. ISIJ 
International 2009, 49 (7), 947. doi: 10.2355/

isijinternational.49.947

(29) Zaitsev, A. I.; Dobrokhotova, Z. V.; Litvina, A. D.; Mogutnov, B. M. Chem. Soc. Faraday Trans. 1995, 91 (4), 703. doi: 10.1039/ft9959100703

(30) Cao, Z. M.; Wang, K. P.; Qiao, Z. Y.; Du, G. W. Acta Phys. -Chim. Sin. 2012, 28 (1), 37. [曹战民, 王昆鹏, 乔芝郁, 杜广巍. 物理化学学报, 2012, 28 (1), 37.] doi: 10.3866/PKU. WHXB201111172

(31) Vogel, R.; Klose, H. Arch. Eisenhuttenwesen 1952, 23 (7), 287.

(32) Kaneko, H.; Nishizawa, T.; Tamaki, K. Nippon Kinzoku Gakkai-shi 1965, 29 (2), 159

(33) Yamada, K.; Kato, E. Tetsu-to-Hagane (J. Iron Steel Inst. Jap.) 1979, 65 (2), 273.

(34) Yamada, K.; Kato, E. Trans. Iron Steel Inst. Jap. 1983, 23 (1), 51. doi: 10.2355/isijinternational1966.23.51

(35) Ding, X.; Wang, W.; Han, Q. Acta Metall. Sin. 1993, 29 (12),
B527.

(36) Raghavan, V. The Al-Fe-P System (Aluminium-IronPhosphorus). In Phase Diagrams of Ternary Iron Alloys, Part 3, Ternary Systems Containing Iron and Phosphorus; Indian Institute of Metals: Calcutta, 1988.

(37) Raghavan, V. Alloy Phase Diagrams 1989, 5 (1), 32.

(38) Schmid-Fetzer, R.; Tomashik, V. A. Landolt-B Rnstein-Group IV Physical Chemistry 2008, $11 D 1$ (1), 172.

(39) Dinsdale, A. T. CALPHAD 1991, 15, 317. doi: 10.1016/03645916(91)90030-N

(40) Muggianu, Y. M.; Gambino, M.; Bros, J. P. Chim. Phys. 1975, 72,83 .

(41) Ansara, I.; Dupin, N.; Lukas, H. L.; Sundman, B. J. Alloy. Compd. 1997, 247, 20. doi: 10.1016/S0925-8388(96)02652-7

(42) Dupin, N.; Ansara, I.; Sundman, B. CALPHAD 2001, 25, 279. doi: 10.1016/S0364-5916(01)00049-9 